\title{
RESEARCH
}

Open Access

\section{The clinical significance of blood lactate levels in evaluation of adult patients with veno-arterial extracorporeal membrane oxygenation}

\author{
Mohamed Laimoud ${ }^{1,2^{*}}$ and and Mosleh Alanazi ${ }^{1}$
}

\begin{abstract}
Background: Veno-arterial ECMO is a life-supporting procedure that can be done to the patients with cardiogenic shock which is associated with hyperlactatemia. The objective of this study was to detect the validity of serial measurements of arterial lactate level in differentiating hospital mortality and neurological outcome after VA-ECMO support for adult patients with cardiogenic shock. All consecutive patients $\geq 18$ years admitted with cardiogenic shock and supported with VA-ECMO between 2015 and 2019 in our tertiary care hospital were retrospectively studied.

Results: The study included 106 patients with a mean age of $40.2 \pm 14.4$ years, a mean BMI of $26.5 \pm 7$ and mostly males (69.8\%). The in-hospital mortality occurred in $56.6 \%$ and acute cerebral strokes occurred in $25.5 \%$ of the enrolled patients. The non-survivors and the patients with acute cerebral strokes had significantly higher arterial lactate levels at pre-ECMO initiation, post-ECMO peak and after $24 \mathrm{~h}$ of ECMO support compared to the survivors and those without strokes, respectively. The peak arterial lactate $\geq 14.65 \mathrm{mmol} / \mathrm{L}$ measured after ECMO support had $81.7 \%$ sensitivity and $89.1 \%$ specificity for predicting hospital mortality [AUROC $0.889, p<0.001$ ], while the arterial lactate level $\geq 3.25 \mathrm{mmol} / \mathrm{L}$ after $24 \mathrm{~h}$ of ECMO support had $88.3 \%$ sensitivity and $97.8 \%$ specificity for predicting hospital mortality [AUROC 0.93, $p<0.001$ ]. The peak lactate $\geq 15.15 \mathrm{mmol} / \mathrm{L}$ measured after ECMO support had $70.8 \%$ sensitivity and $69 \%$ specificity for predicting cerebral strokes [AUROC $0.717, p<0.001$ ], while the lactate level $\geq 3.25 \mathrm{mmol} / \mathrm{L}$ after $24 \mathrm{~h}$ of ECMO support had $79.2 \%$ sensitivity and $72.4 \%$ specificity for predicting cerebral strokes [AUROC 0.779, $p<0.001$ ]. Progressive hyperlactatemia (OR $=1.427,95 \% \mathrm{Cl} 1.048-1.944, p=0.024)$ and increasing SOFA score after $48 \mathrm{~h}(\mathrm{OR}=1.819,95 \% \mathrm{Cl} 1.374-2.409, p<0.001)$ were significantly associated with in-hospital mortality after VA-ECMO support. Post hoc analysis detected a significantly high frequency of hypoalbuminemia in the non-survivors and in the patients who developed acute cerebral strokes during VA-ECMO support.

Conclusion: Progressive hyperlactatemia after VA-ECMO initiation for adult patients with cardiogenic shock is a sensitive and specific predictor of hospital mortality and acute cerebrovascular strokes. According to our results, we could recommend early VA-ECMO initiation to achieve adequate circulatory support and better outcome.
\end{abstract}

Keywords: Lactate, VA-ECMO, SOFA, Cerebrovascular stroke, Cardiogenic shock, Mortality, Hypoalbuminemia

\footnotetext{
* Correspondence: mlaimoud@kfshrc.edu.sa; m.laimoud@hotmail.com

${ }^{1}$ Adult Cardiac Surgical Intensive Care Unit (CSICU), King Faisal Specialist

Hospital \& Research Center, Riyadh, Saudi Arabia

${ }^{2}$ Critical Care Medicine Department, Cairo University, Cairo, Egypt
}

\section{Springer Open}

(c) The Author(s). 2020 Open Access This article is licensed under a Creative Commons Attribution 4.0 International License, which permits use, sharing, adaptation, distribution and reproduction in any medium or format, as long as you give appropriate credit to the original author(s) and the source, provide a link to the Creative Commons licence, and indicate if changes were made. The images or other third party material in this article are included in the article's Creative Commons licence, unless indicated otherwise in a credit line to the material. If material is not included in the article's Creative Commons licence and your intended use is not permitted by statutory regulation or exceeds the permitted use, you will need to obtain permission directly from the copyright holder. To view a copy of this licence, visit http://creativecommons.org/licenses/by/4.0/. 


\section{Background}

Veno-arterial extracorporeal membrane oxygenation (VA-ECMO) is a life-supporting procedure that can be given to the patients with cardiac dysfunctions requiring urgent cardiopulmonary support [1]. Cardiogenic shock is an emergency with a high mortality despite all efforts in diagnostic and therapeutic managements. The critical reduction of oxygen supply and organ perfusion during the shock state are associated with affection of the end organs like the brain, kidney and gastrointestinal tract resulting in multi-organ dysfunction syndrome [2-4].

Lactate is a metabolite produced during anaerobic glycolysis with impaired oxygen delivery and tissue perfusion. Hyperlactatemia was described in cardiogenic shock due to sympathetic nervous activation, accelerated glycolysis and metabolism with the use of inotropic drugs $[5,6]$. Hyperlactatemia has been proven to be associated with increased mortality among different critically ill patients including those after cardiac surgeries [7-9]. The objective of this study was to detect the validity of serial measurements of arterial lactate level in differentiating in-hospital mortality and neurological outcome after VA-ECMO support for patients with cardiogenic shock.

\section{Methods}

\section{Patients selection}

All consecutive patients $\geq 18$ years old with cardiogenic shock who received VA-ECMO support at our tertiary care hospital between 2015 and 2019 were retrospectively enrolled in this study. We excluded the patients who had cardiac arrest and cardiopulmonary resuscitation (CPR). Our study was approved by the hospital ethics committee without a need to get informed consents because of being retrospective. The Integrated Compliance Information System (ICIS) provided the database to get the clinical and laboratory variables of the enrolled patients.

\section{ECMO equipment and circuits}

The studied patients got extracorporeal cardiopulmonary support via Maquet Cardiohelp and Rotaflow ECMO machines (Getinge group, Germany). Our hospital has 8 ECMO machines restricted to the cardiac critical care units. There are 3 Cardiohelp devices with the serial numbers 90410540, 90410543 and 90410542 and 5 Rotaflow devices with the serial numbers 90430365, 90430366, 90430367, 90430642 and 90430186 . We have used Maquet HeartLung Support (HLS) module advanced and cannulae which are biocompatible with Bioline coating. The module consist of a low-damage centrifugal pump with an oxygenator and integrated sensors that allow bubble detection and continuous measurements of haemoglobin, haematocrite, venous oxygen saturation, module internal pressure, venous and arterial pressures and temperatures.

\section{ECMO initiation and patients management}

Veno-arterial ECMO support was indicated during cardiac surgery due to either failed weaning from cardiopulmonary bypass or rapid haemodynamic deterioration after weaning. Pre-operative VA-ECMO or ECMO without cardiotomy were initiated for refractory cardiogenic shock despite optimal resuscitation efforts.

After ECMO initiation, the blood flow was adjusted according to clinical assessments including urine output, clearance of hyperlactatemia and mixed venous oxygen saturation. Blood lactate levels were measured by arterial blood gas analysis which had been done hourly in the first few hours after ECMO initiation till haemodynamics stabilization then every $2 \mathrm{~h}$ till clearance.

Titration of oxygen flow and sweep flow were gradually done to achieve acceptable blood gases. The temperature of heat exchanger was adjusted to maintain the normal body temperature and avoiding hypothermia especially post-cardiotomy. Minimizing the doses of inotropic drugs was done to help myocardial recovery but keeping ventricular ejection to avoid ventricular thrombosis. Midazolam and morphine intravenous infusions were routinely used to achieve adequate sedation and analgesia. All studied patients were mechanically ventilated on the pressure regulated volume-controlled (PRVC) mode at 10 breaths/ min with a low tidal volume of $6-8 \mathrm{ml} / \mathrm{kg}$, a positive endexpiration pressure (PEEP) of $6-8 \mathrm{mmHg}$ and the inspired oxygen fraction was $30-40 \%$.

Anticoagulation was done via intravenous unfractionated heparin infusion which was adjusted according to heparin assay (target $0.3-0.7$ units $/ \mathrm{ml}$ ), antithrombin III (goal $80-120 \%$ ) and clinical tolerance. Platelets were transfused to keep count more than $50\left(10^{9} / \mathrm{L}\right)$, packed red blood corpuscles were transfused to maintain the haematocrite at $30-35 \%$ and cryoprecipitate transfusions were given to keep fibrinogen level more than $1(\mathrm{gm} / \mathrm{L})$.

All studied patients underwent daily neurological evaluation after withdrawal of sedation including Glasgow Coma Scale assessment, pupil sizes and reactivity to light and brain stem reflexes. Continuous brain oxygenation monitoring (rSO2\%) was routinely done to our VA-ECMO-supported patients using the near-infrared spectroscopy (NIRS) technique via frontal probes. If any neurological manifestations after sedation withdrawal or significant $\mathrm{rSO} 2 \%$ change happened, brain computed tomography $(\mathrm{CT})$ imaging was done as early as possible.

\section{Studied variables}

The clinical and laboratory data of studied patients were collected. The blood lactate levels were collected at 3 points: pre-ECMO initiation, peak level and $24 \mathrm{~h}$ after 
ECMO support. The Sequential Organ Failure Assessment (SOFA) score was calculated on ICU admission and ECMO initiation then after $48 \mathrm{~h}$ to get the $\triangle$ SOFA. The worst values for each variable were used during SOFA calculation. All studied patients were divided according to mortality into the survivors and non-survivors and according to neurological manifestations into 2 groups: cerebral damage and non-cerebral damage groups.

\section{Statistical analysis}

Data were analysed using the Statistical Package of Social Science Software program, version 23 (SPSS). The continuous variables were described as mean \pm standard deviation (SD) or median with interquartile range (IQR), while the nominal variables were reported as total number and percentages. $p$ value of less than 0.05 was considered statistically significant. Kolmogorov-Smirnov test was used as a normality test to evaluate the variables and choose the type of statistical tests. Receiver operating characteristic (ROC) curves were done to evaluate the ability of blood lactate level to predict hospital mortality and neurological damage. In this analysis, area under ROC curve (AUROC) was calculated to quantify the accuracy of the predictive model.

\section{Results}

\section{Baseline and clinical data}

We studied 106 consecutive adult patients with cardiogenic shock that failed medical management and required VA-ECMO support. The mean age of studied

Table 1 Baseline and clinical data of studied VA-ECMO-treated patients

\begin{tabular}{|c|c|c|c|c|c|c|c|}
\hline \multicolumn{2}{|l|}{ Studied variables } & $\begin{array}{l}\text { Survivors } \\
(n=46,43.4 \%)\end{array}$ & $\begin{array}{l}\text { Non-survivors } \\
(n=60,56.6 \%)\end{array}$ & $p$ value & $\begin{array}{l}\text { Cerebral damage } \\
(n=27,25.5 \%)\end{array}$ & $\begin{array}{l}\text { No cerebral damage } \\
(n=79,74.5 \%)\end{array}$ & $p$ value \\
\hline \multicolumn{2}{|l|}{ Age } & $39 \pm 10.9$ & $41.1 \pm 16.6$ & 0.73 & $40.7 \pm 16.2$ & $39.7 \pm 12.8$ & 0.78 \\
\hline \multicolumn{2}{|l|}{ BMl } & $26.4 \pm 6.6$ & $26.6 \pm 7.4$ & 0.82 & $25 \pm 7.2$ & $27.7 \pm 6.6$ & 0.031 \\
\hline \multirow[t]{2}{*}{ Sex } & Males & $31(67.4)$ & $43(71.7)$ & 0.61 & $19(70.4)$ & 55 (69.6) & 0.52 \\
\hline & Females & $15(32.6)$ & $17(28.3)$ & & $8(29.6)$ & $24(30.4)$ & \\
\hline \multicolumn{2}{|l|}{ CKD } & $2(4.3)$ & $19(31.7)$ & 0.001 & $8(29.7)$ & $13(16.5)$ & 0.028 \\
\hline \multicolumn{2}{|l|}{ DM } & $9(19.6)$ & $11(18.3)$ & 0.84 & $6(22.2)$ & $14(17.7)$ & 0.598 \\
\hline \multicolumn{2}{|l|}{ Systemic hypertension } & $14(30.4)$ & $20(33.3)$ & 0.75 & $9(33.3)$ & 25 (31.6) & 0.801 \\
\hline \multicolumn{2}{|l|}{ LV EF\% } & $29.2 \pm 13.9$ & $29.6 \pm 13.9$ & 0.73 & $30.9 \pm 13.3$ & $28.3 \pm 14.3$ & 0.15 \\
\hline \multicolumn{2}{|l|}{ Cardiac surgeries } & $21(45.7)$ & $40(66.7)$ & 0.03 & $18(66.7)$ & $43(54.4)$ & 0.03 \\
\hline \multicolumn{2}{|l|}{ CPB time (min) } & $213.4 \pm 83.3$ & $239.9 \pm 97.6$ & 0.43 & $261.6 \pm 103.4$ & $195.8 \pm 65.5$ & 0.007 \\
\hline \multicolumn{2}{|c|}{ Aortic clamping time (min) } & $144.3 \pm 51.7$ & $148.6 \pm 54.6$ & 0.85 & $160.2 \pm 57.5$ & $130.1 \pm 42.1$ & 0.03 \\
\hline \multicolumn{2}{|l|}{ ECMO days } & $10.1 \pm 6.6$ & $9.5 \pm 7.7$ & 0.21 & $10.4 \pm 8.3$ & $9.2 \pm 6.2$ & 0.80 \\
\hline \multirow[t]{2}{*}{ Cannulation strategy } & Peripheral & $33(71.7)$ & $27(45)$ & 0.006 & $12(44.4)$ & $48(60.8)$ & 0.03 \\
\hline & Central & $13(28.3)$ & $33(55)$ & & 15 (55.6) & $31(39.2)$ & \\
\hline \multicolumn{2}{|l|}{ IABP } & $12(26.1)$ & $9(15)$ & 0.15 & $6(22.2)$ & 15 (18.9) & 0.810 \\
\hline \multicolumn{2}{|l|}{ ICU days } & $20(14-57)$ & $14(5.5-30.5)$ & 0.002 & $19(6-40)$ & $15.5(11-29)$ & 0.04 \\
\hline \multicolumn{2}{|l|}{ Ventilator days } & $9(8-26)$ & $13.5(5-25.5)$ & 0.95 & $15(5.5-31.5)$ & $9(8-16)$ & 0.09 \\
\hline \multicolumn{2}{|l|}{ AKI } & $21(45.7)$ & $52(86.7)$ & $<0.001$ & $23(85.2)$ & $41(51.9)$ & 0.001 \\
\hline \multicolumn{2}{|l|}{ Haemodialysis } & $9(19.6)$ & $41(68.3)$ & $<0.001$ & $17(63)$ & $26(32.9)$ & 0.001 \\
\hline \multicolumn{2}{|l|}{ SOFA on admission } & $10.9 \pm 2.8$ & $15.6 \pm 2.9$ & $<0.001$ & $14.9 \pm 3.1$ & $12.5 \pm 3.8$ & $<0.001$ \\
\hline \multicolumn{2}{|l|}{ SOFA after $48 \mathrm{~h}$} & $8.8 \pm 2.6$ & $19.2 \pm 2.5$ & $<0.001$ & $17.7 \pm 4.8$ & $12.2 \pm 5.3$ & $<0.001$ \\
\hline \multicolumn{2}{|l|}{$\triangle \mathrm{SOFA}$} & $-2.1 \pm 1.9$ & $3.6 \pm 1.7$ & $<0.001$ & $2.8 \pm 2.7$ & $-0.3 \pm 3.1$ & $<0.001$ \\
\hline \multicolumn{2}{|l|}{ Atrial fibrillation } & $14(30.4)$ & $40(66.7)$ & 0.001 & $18(66.7)$ & $36(45.6)$ & 0.001 \\
\hline \multicolumn{2}{|l|}{ Intracardiac thrombi } & $2(4.3)$ & $5(8.3)$ & 0.69 & $5(18.5)$ & $2(2.5)$ & 0.04 \\
\hline \multicolumn{2}{|l|}{ ECMO circuit thrombi } & $2(4.3)$ & $4(6.7)$ & 0.69 & $5(18.5)$ & $1(1.3)$ & 0.08 \\
\hline \multicolumn{2}{|l|}{ Acute strokes } & $5(10.9)$ & $22(36.7)$ & 0.006 & --- & --- & --- \\
\hline \multicolumn{2}{|l|}{ Thrombotic stroke } & $4(8.7)$ & $10(16.7)$ & 0.11 & --- & --- & --- \\
\hline \multicolumn{2}{|l|}{ Intracerebral bleeding } & $1(2.2)$ & $12(20)$ & 0.006 & --- & --- & --- \\
\hline \multicolumn{2}{|l|}{ Hospital mortality } & --- & --- & --- & $23(85.2)$ & $37(46.8)$ & $<0.001$ \\
\hline
\end{tabular}

Data are presented mean $\pm \mathrm{SD}$, median (IQR) or $N(\%)$ 
patients was $40.2 \pm 14.4$ years with a mean BMI of 26.5 \pm 7 and mostly males (69.8\%). About 61 (57.5\%) patients were supported with VA-ECMO because of postcardiotomy cardiogenic shock. The in-hospital mortality occurred in $56.6 \%$ while the acute cerebrovascular strokes occurred in $25.5 \%$ of the studied patients. According to brain imaging, ischemic strokes were diagnosed in 14 (13.2\%) patients while intracerebral bleeding occurred in 13 (12.3\%) patients.

The non-survivors group had significantly frequent chronic kidney disease (CKD), cardiac surgeries, AKI, renal replacement therapy and longer ICU stay compared to the survivors group. The non-survivors had higher mean initial SOFA score with an increased trend after $48 \mathrm{~h}$ compared to the survivors. The patients with acute cerebral strokes had significantly frequent CKD, cardiac surgeries, longer $\mathrm{CPB}$ and aortic cross clamping times, lesser BMI and longer ICU stay compared to the patients without cerebral damage. The patients who developed acute cerebral strokes had higher mean initial SOFA score with an increased trend after $48 \mathrm{~h}$ compared to those who did not develop brain damage. Atrial fibrillation was a significant finding in the non-survivors and the patients with cerebral damage. The non-survivors had significantly frequent intracerebral bleeding and the patients with cerebral damage had significantly high hospital mortality. Central VA-ECMO cannulation was significantly frequent in the non-survivors and those with cerebral damage (Table 1).

\section{Laboratory data of studied patients}

The pre-ECMO mean blood lactate level was $4.4 \pm 1.5$ vs $7.2 \pm 2(p<0.001)$ and the median base excess was -6.1 $[-10.2$ to -5.4$]$ vs $-10.1[-13$ to -7.7$](p<0.001)$ in the survivors and non-survivors, respectively. The pre-ECMO mean blood lactate level was $6.8 \pm 2.2$ vs $5.3 \pm 2.1$ ( $p=$ $0.001)$ and the median base excess was $-10.1[-12.9$ to $7.2]$ vs -7 [ -11.2 to -5.6$](p=0.004)$ in the patients with and without cerebral damage, respectively. After ECMO support, the mean peak arterial blood lactate level was 11 \pm 3 vs $16.7 \pm 3.3(p<0.001)$ and mean blood lactate after $24 \mathrm{~h}$ was $2.2 \pm 0.9$ vs $7.9 \pm 5.7(p<0.001)$ in the survivors and non-survivors groups, respectively. The mean peak lactate level was $16 \pm 3.9$ vs $12.8 \pm 4(p<0.001)$ and mean lactate level after $24 \mathrm{~h}$ was $7.8 \pm 6$ vs $3.5 \pm 3.3(p<0.001)$ in the patients with and without cerebrovascular strokes, respectively (Table 2, Fig. 1).

As compared to the survivors, the non-survivors had significant hypoalbuminemia $(p=0.007)$ and higher serum creatinine level $(p=0.018)$. As compared to the patients without cerebral damage, the patients with cerebrovascular strokes had significant hypoalbuminemia ( $p$ $=0.012)$ and hypofibrinogenemia $(p=0.006)($ Table 2$)$.

\section{Analysis of lactate levels in patients differentiation} Initial blood lactate $\geq 5.25 \mathrm{mmol} / \mathrm{L}$ measured at ECMO initiation had $86 \%$ sensitivity and $84.8 \%$ specificity for predicting hospital mortality [AUROC 0.879, 95\% CI $0.809-0.948 ; p<0.001$ ] with $87.5 \%$ positive predictive value (PPV), $83 \%$ negative predictive value (NPV) and $83 \%$ accuracy. The peak blood lactate $\geq 14.65 \mathrm{mmol} / \mathrm{L}$ measured after ECMO support had $81.7 \%$ sensitivity and $89.1 \%$ specificity for predicting hospital mortality [AUROC 0.889, 95\% CI 0.825-0.953; $p<0.001$ ] with 90.7\% PPV, 78.8\% NPV and $84.9 \%$ accuracy. The blood lactate level $\geq 3.25 \mathrm{mmol} / \mathrm{L}$ after $24 \mathrm{~h}$ of ECMO support had $88.3 \%$ sensitivity and $97.8 \%$ specificity for predicting hospital mortality [AUROC $0.93,95 \%$ CI $0.878-0.983 ; p$ $<0.001$ ] with 97.8\% PPV, 86.5\% NPV and 92.5\% accuracy (Table 3, Fig. 2).

Table 2 Laboratory workup at ECMO insertion

\begin{tabular}{|c|c|c|c|c|c|c|}
\hline Laboratory items & Survivors & Non-survivors & $p$ value & Cerebral damage & No cerebral damage & $p$ value \\
\hline Haemoglobin (g/L) & $114.2 \pm 17.4$ & $113.6 \pm 21.6$ & 0.78 & $118.5 \pm 23$ & $111.3 \pm 16.2$ & 0.13 \\
\hline Platelet count $\left(10^{9} / \mathrm{L}\right)$ & $177.9 \pm 85.4$ & $154.2 \pm 94.2$ & 0.11 & $149.7 \pm 92.4$ & $176.7 \pm 88.4$ & 0.09 \\
\hline aPTT (seconds) & $44.4 \pm 12.1$ & $56.7 \pm 32.2$ & 0.06 & $59.8 \pm 34.4$ & $44.4 \pm 13.3$ & 0.012 \\
\hline PTT ratio & $1.3 \pm 0.4$ & $1.6 \pm 0.9$ & 0.14 & $1.7 \pm 1$ & $1.3 \pm 0.4$ & 0.008 \\
\hline INR & $1.7 \pm 0.6$ & $1.7 \pm 0.4$ & 0.75 & $1.7 \pm 0.4$ & $1.7 \pm 0.6$ & 0.75 \\
\hline Fibrinogen (g/L) & $3.5 \pm 1.4$ & $3 \pm 1.1$ & 0.24 & $2.9 \pm 1.3$ & $3.5 \pm 1.2$ & 0.006 \\
\hline Base excess (mmol/L) & $-6.1(-10.2$ to -5.4$)$ & $-10.1(-13$ to -7.7$)$ & $<0.001$ & $-10.1(-12.9$ to -7.2$)$ & $-7(-11.2$ to -5.6$)$ & 0.004 \\
\hline Pre-ECMO lactate (mmol/L) & $4.4 \pm 1.5$ & $7.2 \pm 2$ & $<0.001$ & $6.8 \pm 2.2$ & $5.3 \pm 2.1$ & 0.001 \\
\hline Peak lactate level (mmol/L) & $11 \pm 3$ & $16.7 \pm 3.3$ & $<0.001$ & $16 \pm 3.9$ & $12.8 \pm 4$ & $<0.001$ \\
\hline Lactate at $24 \mathrm{~h}(\mathrm{mmol} / \mathrm{L})$ & $2.2 \pm 0.9$ & $7.9 \pm 5.7$ & $<0.001$ & $7.8 \pm 6$ & $3.5 \pm 3.3$ & $<0.001$ \\
\hline Serum creatinine $(\mu \mathrm{mol} / \mathrm{L})$ & $96.4 \pm 46$ & $125.5 \pm 74.2$ & 0.018 & $117.5 \pm 74.9$ & $109 \pm 55.6$ & 0.87 \\
\hline Serum bilirubin $(\mu \mathrm{mol} / \mathrm{L})$ & $28.6(15.7-58.7)$ & $37(22-61.7)$ & 0.09 & $31.9(22.8-55.1)$ & $29.5(15.7-58.9)$ & 0.51 \\
\hline Serum albumin (g/L) & $34.3 \pm 5.9$ & $31.4 \pm 5.5$ & 0.007 & $30.9 \pm 6.3$ & $34.1 \pm 5$ & 0.012 \\
\hline
\end{tabular}

Data are presented mean $\pm \mathrm{SD}$, median (IQR) or $N(\%)$ 


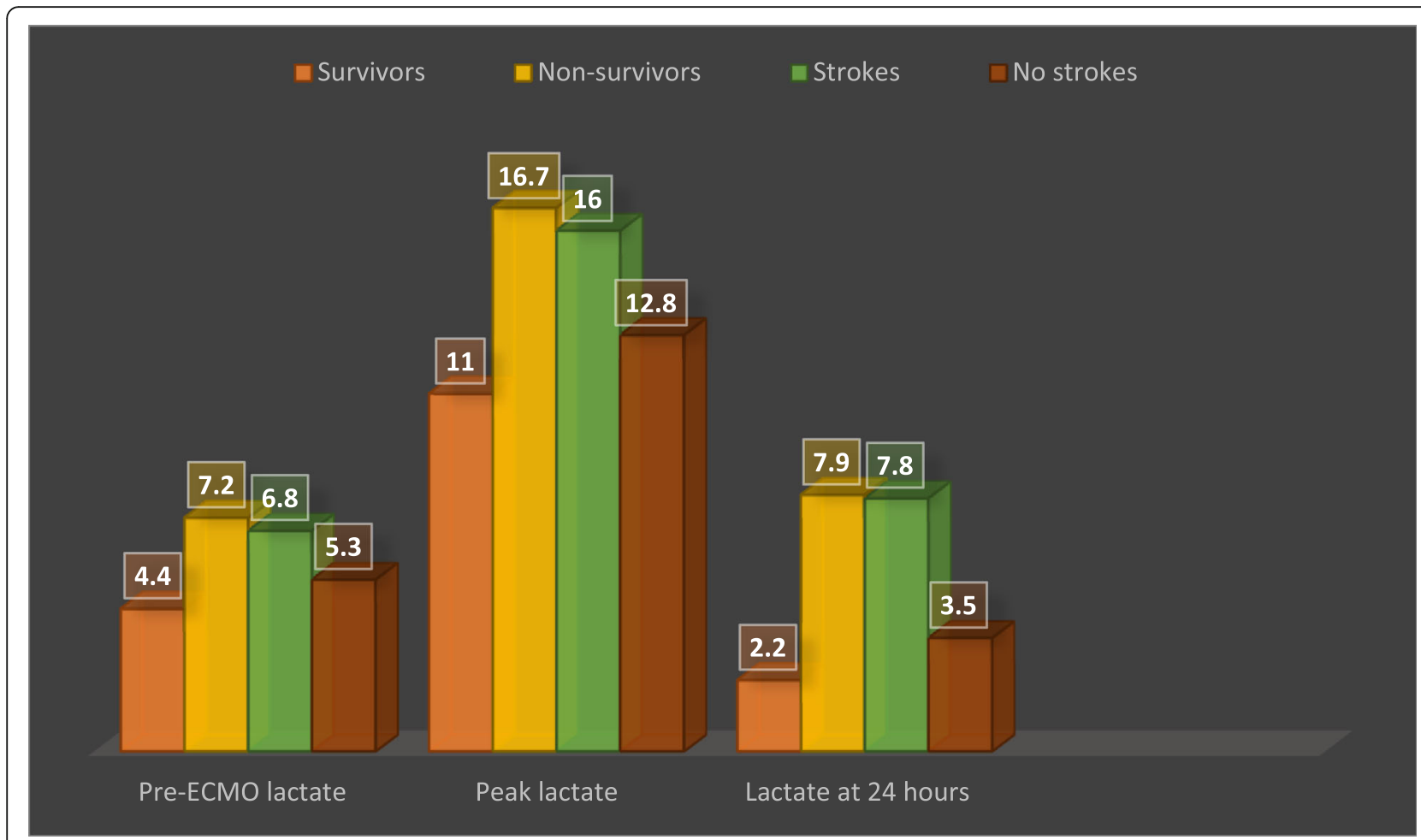

Fig. 1 The mean blood lactate levels of studied VA-ECMO-treated patients

Initial blood lactate $\geq 5.25 \mathrm{mmol} / \mathrm{L}$ measured at ECMO initiation had $75.6 \%$ sensitivity and $62.1 \%$ specificity for predicting cerebral damage [AUROC 0.685 , 95\% CI $0.582-0.788 ; p<0.001]$ with $60.7 \%$ PPV, $76.6 \% \mathrm{NPV}$ and $68 \%$ accuracy. The peak blood lactate $\geq 15.15 \mathrm{mmol} / \mathrm{L}$ measured after ECMO support had $70.8 \%$ sensitivity and $69 \%$ specificity for predicting cerebral damage [AUROC 0.717, 95\% CI 0.616-0.819; $p<0.001$ ] with $65.4 \% \mathrm{PPV}, 74.1 \% \mathrm{NPV}$ and $69.8 \%$ accuracy. The lactate level $\geq 3.25 \mathrm{mmol} / \mathrm{L}$ after $24 \mathrm{~h}$ of ECMO support had $79.2 \%$ sensitivity and $72.4 \%$ specificity for predicting cerebral damage [AUROC 0.779, 95\% CI 0.686-0.871; $p<0.001$ ] with 70.4\% PPV, $80.8 \%$ NPV and $75.5 \%$ accuracy (Table 4, Fig. 3 ).

\section{Mortality multivariable analysis}

A multivariable regression analysis was done to get the odds ratio with the hospital mortality as the dependent variable. Progressive hyperlactatemia $(\mathrm{OR}=1.427,95 \% \mathrm{CI}$ $1.048-1.944, p=0.024)$ and increasing SOFA score after $48 \mathrm{~h}(\mathrm{OR}=1.819,95 \%$ CI $1.374-2.409, p<0.001)$ were significantly associated with in-hospital mortality after VA-ECMO support. Despite haemodialysis central ECMO cannulation, AF and cardiac surgeries were significant in the non-survivors group in the univariate analysis, there were not significantly associated with mortality in the multivariable regression analysis (Table 5).

\section{Discussion}

Veno-arterial ECMO is used in cases of refractory cardiogenic shock including post-cardiotomy shock to rapidly achieve circulatory support and protect organs perfusion allowing time for cardiac recovery and avoiding multiorgan system failure. Our study revealed in-hospital mortality of $56.6 \%$ which is consistent with other large ECMO registries [10-12]. Progressive hyperlactatemia and delayed clearance during the first $24 \mathrm{~h}$ after ECMO support were associated with the increased mortality in our both univariate and multivariate analysis $(\mathrm{OR}=1.427,95 \% \mathrm{CI}$ 1.048-1.944, $p=0.024$ ). The non-survivors had significantly higher pre-ECMO lactate level and metabolic acidosis as compared to the survivors.

Table 3 The validity measures of blood lactate in differentiating mortality

\begin{tabular}{lllllllll}
\hline Blood lactate & AUROC & $\mathbf{9 5} \% \mathbf{C l}$ & Cut-off & Sensitivity & Specificity & PPV & NPV & Accuracy \\
\hline Pre-ECMO lactate & 0.879 & $0.809-0.948$ & $\geq 5.25$ & $86.0 \%$ & $84.8 \%$ & $87.5 \%$ & $83.0 \%$ & $83.0 \%$ \\
Lactate peak & 0.889 & $0.825-0.953$ & $\geq 14.65$ & $81.7 \%$ & $89.1 \%$ & $90.7 \%$ & $78.8 \%$ & $84.9 \%$ \\
Lactate after 24h & 0.930 & $0.878-0.983$ & $\geq 3.25$ & $88.3 \%$ & $97.8 \%$ & $98.1 \%$ & $86.5 \%$ & $92.5 \%$ \\
\hline
\end{tabular}



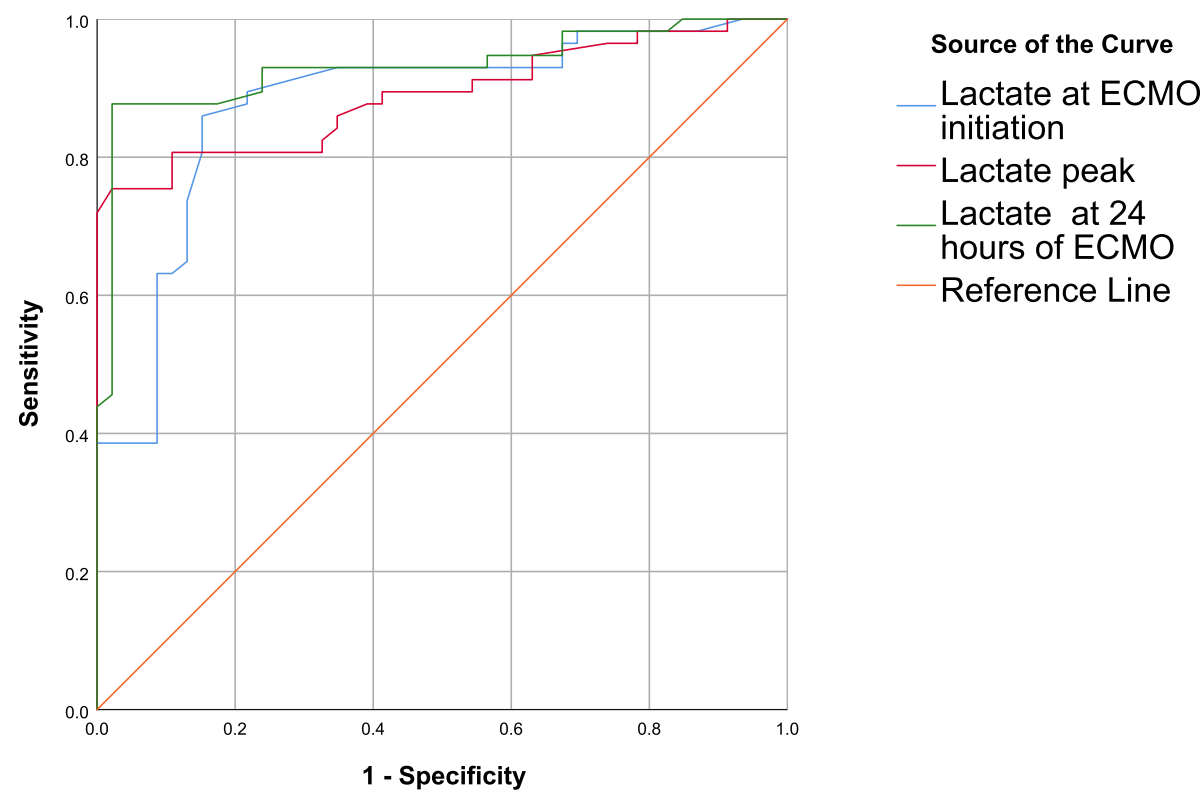

Fig. 2 ROC of blood lactate in differentiating mortality of VA-ECMO-treated patients

Schmidt et al. [10] described the association of preECMO significant metabolic acidosis and mortality but did not describe the lactate level in those patients. Chen et al. [13] described the pre-ECMO greater metabolic acidosis and hyperlactatemia in the non-survivors supported with VA-ECMO and used pre-ECMO lactate level to develop the modified SAVE score.

Our results showed that the peak blood lactate had a better performance (AUROC 0.889, 95\% CI 0.825-0.953; $p<0.001$ ) and lactate level after $24 \mathrm{~h}$ of ECMO initiation had the best performance regarding sensitivity and specificity in differentiating mortality (AUROC 0.93, 95\% CI 0.878-0.983; $p<0.001)$. This finding can be explained by impaired tissue perfusion despite achieving haemodynamic stabilization and the use of inotropic drugs. The use of $\beta$ adrenergic stimulants accelerates glycolysis and gluconeogenesis with increases in blood lactate levels [14, 15]. Li et al. [16] described the negative correlation between blood levels of lactate after ECMO initiation and the mean arterial blood pressure (MAP) and suggested that achieving higher MAP might reduce lactate levels.

Rastan et al. [17] studied VA-ECMO support for postcardiotomy shock and described blood lactate level more than $10 \mathrm{mmol} / \mathrm{L}$ immediately after ECMO initiation as a significant predictor of mortality (mortality $83.0 \%$; OR 2.65; $p<0.001$ ) while persistently high lactate levels more than $10 \mathrm{mmol} / \mathrm{L}$ after 24 and $48 \mathrm{~h}$ of ECMO initiation were associated with the highest mortalities of $93.6 \%$ and $97.6 \%$, respectively.

In our analysis, we found the presence of pre-ECMO chronic renal impairment or development of postECMO acute kidney injury and haemodialysis were highly significant in the non-survivors. Schmidt et al. [10] described the presence of renal failure as a significant variable in the mortality group after VA-ECMO support. However Aso et al. [18] found that renal impairment was not a significant variable but the use of haemodialysis was significantly associated with mortality in VA-ECMO-treated patients. Rastan et al. [17] described the development of acute renal failure or acute hepatic failure as predictors of mortality.

We used the SOFA scoring to assess the magnitude of organ failure and to detect the trend after ECMO support. The non-survivors had higher mean initial SOFA score with an increasing trend compared to the survivors. Together with rising blood lactate level, the increasing SOFA score after $48 \mathrm{~h}$ of VA-ECMO support were the predictors of hospital mortality in our multivariate regression analysis. Ferreira et al. [19] described

Table 4 The validity measures of blood lactate in differentiating cerebral damage

\begin{tabular}{lllllllll}
\hline Blood lactate & AUROC & $\mathbf{9 5 \% C l}$ & Cut-off & Sensitivity & Specificity & PPV & NPV & Accuracy \\
\hline Pre-ECMO lactate & 0.685 & $0.582-0.788$ & $\geq 5.25$ & $75.6 \%$ & $62.1 \%$ & $60.7 \%$ & $76.6 \%$ & $68.0 \%$ \\
Lactate peak & 0.717 & $0.616-0.819$ & $\geq 15.15$ & $70.8 \%$ & $69.0 \%$ & $65.4 \%$ & $74.1 \%$ & $69.8 \%$ \\
Lactate after 24h & 0.779 & $0.686-0.871$ & $\geq 3.25$ & $79.2 \%$ & $72.4 \%$ & $70.4 \%$ & $80.8 \%$ & $75.5 \%$ \\
\hline
\end{tabular}



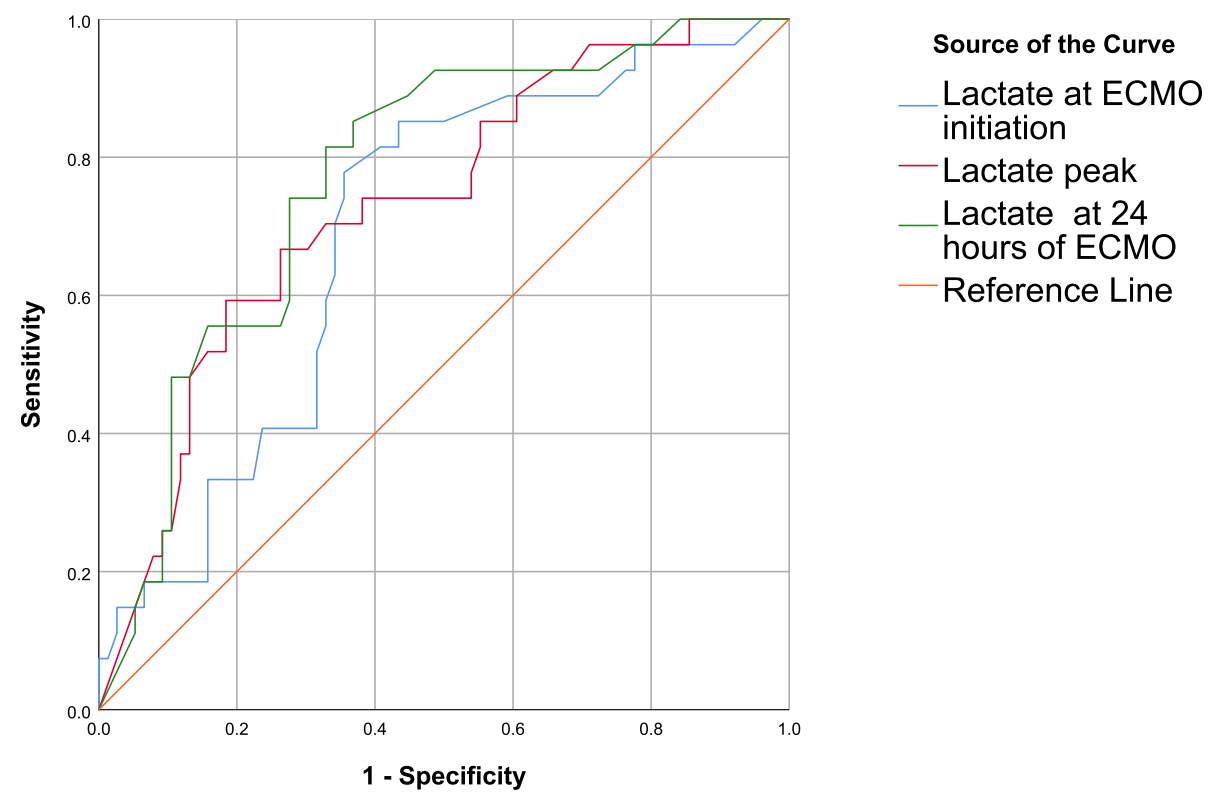

Fig. 3 ROC of blood lactate in differentiating cerebral damage of VA-ECMO-treated patients

the efficacy SOFA scoring of patients during first few days of ICU admission and described the SOFA trend during the first $48 \mathrm{~h}$ as a predictor of outcome regardless of the initial SOFA.

Our results showed that acute cerebrovascular strokes occurred in $25.5 \%$ of patients which is comparable to other studies of acute cerebral strokes during VAECMO support especially post-cardiotomies $[17,20]$. The blood lactate level after ECMO support was linked to the neurological injury and other outcomes in different studies but with different cut-off values $[9,17,20]$.

Our post hoc analysis detected a significantly high frequency of hypoalbuminemia in the non-survivors and in the patients who developed acute cerebral strokes during VA-ECMO support. The hypoalbuminemia was linked to a higher mortality in all hospitalized patients in some studies [21, 22]. Other studies described the occurrence of hypoalbuminemia in some patients admitted with acute large cerebrovascular strokes in haemodynamically stable patients and the low albumin level was linked to mortality of those patients [23, 24]. Recently, Huang

Table 5 Multivariable regression analysis for mortality of VAECMO-treated patients

\begin{tabular}{llll}
\hline Variables & $\boldsymbol{p}$ value & OR & $\mathbf{9 5 \% ~ C l}$ for OR \\
\hline Lactate peak & 0.024 & 1.427 & $1.048-1.944$ \\
Haemodialysis & 0.315 & 4.126 & $0.344-51.669$ \\
Atrial fibrillation & 0.07 & 3.268 & $0.786-31.26$ \\
Cardiac surgeries & 0.217 & 3.482 & $0.480-25.152$ \\
$\Delta$ SOFA & $<0.001$ & 1.819 & $1.374-2.409$ \\
Central VA-ECMO & 0.12 & 3.931 & $0.482-24.16$ \\
\hline
\end{tabular}

et al. described hypoalbuminemia as being strongly associated with mortality of VA-ECMO-treated patients [25].

Finally, our study revealed that the hospital mortality and neurological outcome of VA-ECMO were significantly associated with the severity of pre-ECMO shock state and the appropriate recovery of organs perfusion after ECMO support as indicated with changes of blood lactate levels. Repeated blood lactate measurements after VA-ECMO initiation help to detect the magnitude and duration of impaired tissue oxygenation and organs perfusion and predict outcome.

\section{Conclusion}

Progressive hyperlactatemia after VA-ECMO initiation for adult patients with cardiogenic shock is a sensitive and specific predictor of hospital mortality and cerebrovascular strokes. According to our results, we recommend early VA-ECMO initiation to achieve adequate circulatory support and better outcome.

\section{Limitations}

Our work was a single-centre retrospective study.

\section{Abbreviations \\ AKI: Acute kidney injury; AF: Atrial fibrillation; aPTT: Activated partial thromboplastin time; BMI: Body mass index; CKD: Chronic kidney disease; Cl: Confidence interval; CPB: Cardio-pulmonary bypass; DM: Diabetes mellitus; IABP: Intra-aortic balloon pump; INR: International normalized ratio; LV EF: Left ventricle ejection fraction; NPV: Negative predictive value; ROC: Receiver operating characteristic; SOFA: Sequential Organ Failure Assessment; OR: Odds ratio; PPV: Positive predictive value; VA-ECMO: Veno- arterial extracorporeal membrane oxygenation}




\section{Acknowledgements}

We would like to thank the Cardiac Surgical Intensive Care Unit (adult CSICU) team of our hospital for their excellent work.

\section{Authors' contributions}

All authors contributed to the research and approved the final manuscript. ML has taken part in the design of the study; collection, analysis and interpretation of the data; and drafting of the manuscript. MA has taken part in the design of the study and analysis, collection and interpretation of the data.

\section{Funding}

The authors did not receive any funding for this study.

\section{Availability of data and materials}

The data used in this study are available from the corresponding author upon a reasonable request.

\section{Ethics approval and consent to participate}

The study was approved by the Ethical Committee of King Faisal Specialist Hospital and Research Center and exempted from a specific consent, being a retrospective analytic study that reveals no identifiable private information. The study was given a reference number 2191042.

\section{Consent for publication}

Not applicable

\section{Competing interests}

The authors had no competing interests to declare.

Received: 18 June 2020 Accepted: 14 October 2020

Published online: 27 October 2020

\section{References}

1. Ventetuolo CE, Muratore CS (2014) Extracorporeal life support in critically ill adults. Am J Respir Crit Care Med 190:497-508

2. Napp LC, Kühn C, Bauersachs J (2017) ECMO in cardiac arrest and cardiogenic shock. Herz. 42:27-44

3. Prondzinsky R, Werdan K, Buerke M (2004) Cardiogenic shock: pathophysiology, clinics, therapeutical options and perspectives. Internist (Berl) 45:284-295

4. Cooper HA, Panza JA (2013) Cardiogenic shock. Cardiol Clin 31:567-580 https://doi.org/10.1016/j.ccl.2013.07.009

5. Levy M.M. Preface biomarkers in critical illness. Crit Care Clin. 2011; 27:xiii-xV.

6. Chioléro RL, Revelly JP, Leverve X, Gersbach P, Cayeux MC, Berger MM, Tappy $L$ (2000) Effects of cardiogenic shock on lactate and glucose metabolism after heart surgery. Crit Care Med 28:3784-3791

7. Shapiro NI, Howell MD, Talmor D, Nathanson LA, Lisbon A, Wolfe RE et al (2005) Serum lactate as a predictor of mortality in emergency department patients with infection. Ann Emerg Med 45:524-528

8. Meregalli A, Oliveira RP, Friedman G (2004) Occult hypoperfusion is associated with increased mortality in hemodynamically stable, high-risk, surgical patients. Crit Care 8:R60-R65

9. Lindsay AJ, Xu M, Sessler DI, Blackstone EH, Bashour CA (2013) Lactate clearance time and concentration linked to morbidity and death in cardiac surgical patients. Ann Thorac Surg 95:486-492

10. Schmidt $M$, Burrell $A$, Roberts $L$ et al (2015) Predicting survival after ECMO for refractory cardiogenic shock: the survival after veno-arterial-ECMO (SAVE)-score. Eur Heart J 36(33):2246-2256

11. Maxwell BG, Powers AJ, Sheikh AY, Lee PHU, Lobato RL, Wong JK (2014) Resource use trends in extracorporeal membrane oxygenation in adults: an analysis of the Nationwide inpatient sample 1998-2009. J Thorac Cardiovasc Surg 148(2):416-421

12. Rayan El Sibai, Rana Bachir and Mazen El Sayed. ECMO use and mortality in adult patients with cardiogenic shock: a retrospective observational study in U.S. hospitals.. BMC Emergency Medicine (2018) 18:20.

13. Chen W-C, Huang K-Y, Yao C-W et al (2016) The modified SAVE score: predicting survival using urgent veno-arterial extracorporeal membrane oxygenation within 24 hours of arrival at the emergency department. Crit Care 20:336
14. Levy B, Perez P, Perny J, Thivilier C, Gerard A (2011) Comparison of norepinephrine-dobutamine to epinephrine for hemodynamics, lactate metabolism, and organ function variables in cardiogenic shock. A prospective, randomized pilot study. Crit Care Med 39:450-455

15. Levy B, Gibot S, Franck P, Cravoisy A, Bollaert P-E (2005) Relation between muscle $\mathrm{Na}+\mathrm{K}+$ ATPase activity and raised lactate concentrations in septic shock: a prospective study. Lancet. 365:871-875

16. Li CL, Wang H, Jia M, Ma N et al (2015) The early dynamic behavior of lactate is linked to mortality in postcardiotomy patients with extracorporeal membrane oxygenation support: a retrospective observational study. J Thorac Cardiovasc Surg 149:1445-1450

17. Rastan AJ, Dege A, Mohr M, Doll N, Falk V, Walther T et al (2010) Early and late outcomes of 517 consecutive adult patients treated with extracorporeal membrane oxygenation for refractory postcardiotomy cardiogenic shock. J Thorac Cardiovasc Surg 139:302-311

18. Aso S, Matsui H, Fushimi K, Yasunaga H (2016) In-hospital mortality and successful weaning from venoarterial extracorporeal membrane oxygenation: analysis of 5,263 patients using a national inpatient database in Japan. Crit Care 20:80

19. Ferreira FL, Bota DP, Bross A, Melot C, Vincent JL (2001) Serial evaluation of the SOFA score to predict outcome in critically ill patients. JAMA. 286(14): $1754-1758$

20. Laimoud M, Ahmed W (2020) Acute neurological complications in adult patients with cardiogenic shock on veno-arterial extracorporeal membrane oxygenation support. Egypt Heart J 72:26

21. Jellinge, M. E., Henriksen, D. P., Hallas, P., \& Brabrand, M. (2014). Hypoalbuminemia is a strong predictor of 30-day all-cause mortality in acutely admitted medical patients: a prospective, observational, cohort study. PLoS One, 9(8), e105983. https://doi.org/https://doi.org/10.1371/ journal.pone.0105983.

22. Akirov A, Masri-Iraqi H, Atamna A, Shimon I. Low albumin levels are associated with mortality risk in hospitalized patients [published correction appears in Am J Med. 2020 Feb 29:-]. Am J Med. 2017;130(12):1465.e11-1465. e19.

23. Dziedzic T, Pera J, Slowik A, Gryz-Kurek EA, Szczudlik A (2007)

Hypoalbuminemia in acute ischemic stroke patients: frequency and correlates. Eur J Clin Nutr 61:1318-1322

24. Vahedi A, Lotfinia I, Sad RB, Halimi M, Baybordi H (2011) Relationship between admission hypoalbuminemia and inhospital mortality in acute stroke. Pak J Biol Sci 14(2):118-122

25. Huang $M$, Ong BH, Hoo AEE et al (2020) Prognostic factors for survival after extracorporeal membrane oxygenation for cardiogenic shock. ASAIO J 66(2): $141-145$

\section{Publisher's Note}

Springer Nature remains neutral with regard to jurisdictional claims in published maps and institutional affiliations.

\section{Submit your manuscript to a SpringerOpen ${ }^{\bullet}$ journal and benefit from:}

- Convenient online submission

- Rigorous peer review

- Open access: articles freely available online

- High visibility within the field

- Retaining the copyright to your article

Submit your next manuscript at $>$ springeropen.com 